use of such bodies as the production committee or works council as means of communication. But no one who studies this symposium of papers, thinking of the avenues of sociological research which they indicate, will be led by that vista to forget the elementary duties which lie to hand for every responsible citizen. We must, indeed, improve our channels and means of communication in both directions, alike between Government and governed, manager and operative; but above all, as Prof. Williamson and the Hon. Karl E. Mundt both indicate, we must so far as is possible replace Government control, direct or indirect, over sources of information and means of communication, by the conscious and spontaneous self-control exercised by those who recognize that a great social system can only be built on rational action and on some sacrifice of personal interest to the welfare of the community.

There are old as well as new techniques which can be used to enable the community to understand the need for this sense of social responsibility. There is no greater danger to a free people than that of dictation or of neglect by the Government to dig deep the channels of assent to legislative or adminis. trative action. The papers in these volumes from the American Academy of Political and Social Science, as well as the discussions at the Dundee meeting of the British Association, demonstrate how grave is the situation and how important it is that further research into this question of communication, its techniques and organisation, should be pressed forward from the point of view of production and national recovery. They show also that all men of goodwill should unite to resist the encroachments on the old freedom of thought and utterance which war-time practices and administrative ineptitude are still making, both in the field of science and in the world at large.

\section{THE PREDICTION OF NATURAL FREQUENCIES OF VIBRATION}

\section{The Escalator Method in Engineering Vibration Problems}

By Joseph Morris. Pp. xv + 270. (London: Chapman and Hall, Ltd., 1947.) 21s, net.

$\mathrm{T}$ HE problem of calculating the natural frequencies of a dynamical system is of considerable technical importance in many branches of engineering and not least in that branch of engineering called instrument,-making. It is important for the designer to be able to predict natural frequencies for two main reasons. First, in order to avoid the occurrence of resonance, that is, agreement of a natural frequency with that of some periodic forcing agency; this is of particular importance in rotating and reciprocating machinery, where persistent resonance in service is dangerous. Secondly, in instruments where response and stimulus should be linearly related over a band of frequencies, approach to resonance cannot be allowed, as this destroys the required characteristic. All this is true of electrical and of electro-mechanical systems as well as of purely mechanical ones.

The main purpose of the book under review is to put forward a method for calculating the natural frequencies and modes of systems having a finite number of degrees of freedom, or which can be represented as such. The special feature of the method, which is indicated by the word 'escalator', is that the solution is worked out in a succession of steps in each of which the number of degrees of freedom is one greater than for the previous step, until the full number in the system is attained. Determinants are not used, and the equations determining the frequencies and modal ratios at each stage are easily constructed from the results obtained at the previous stage.

The reviewer believes the method to be new, and the examples included in the book amply demonstrate that it is workable and useful in the hands of an expert. Whether the inventor's great enthusiasm for the method is fully justified only experience can settle. Undoubtedly the method is particularly well suited to those problems where most of the dynamical system is constant but where parts of it are subject to variation, for it may be possible so to arrange the calculations that the variable elements only appear in the last stages of the 'escalator'. When this is so, considerable saving in labour may result. It is just on the question of economy of labour for results of given accuracy that the method must be judged, as it has no advantage of elegance and, of course, it yields theoretically the same results as orthodox processes. It should be added that the special advantage just mentioned is not peculiar to the Morris escalator; it is shared to some extent, for example, by the method of partition or of submatrices.

The contents of the book are considerably wider than the title would indicate, for the first seven chapters are devoted to discussions of problems in the statics of beams and structures. A welcome feature is the inclusion here of a chapter on the Hardy Cross method and some of its extensions, but the author does not remark the fact that all such methods are essentially the same as the Gauss-Seidel method for the iterative solution of simultaneous linear equations. Applications of the escalator process, for the most part to problems arising in aeronautics, occupy the last eleven chapters.

Unquestionably the author has written a stimulating and useful book which embodies the results of many years of enthusiastic work, and he is to be congratulated on bringing this to fruition. The reviewer must express his regret that the author has never adopted the notation of matrices in his work on vibrations and structures, since the gain in clarity and conciseness is enormous. W. J. DuncaN

\section{THE FINAL INTEGRATION}

The Integrative Action of the Nervous System By Sir Charles Sherrington. With a new Foreword by the Author and a Bibliography of his Writings. Pp. xxvi+433. (Cambridge: At the University Press, 1947.) 25s. net.

TN July the seventeenth meeting of the International 1 Physiological Congress was held in Oxford. It was the first since the meeting at Zurich in 1938, and like other post-war congresses it was a most enjoyable reunion. The organising committee had many problems to face in planning for a meeting with an attendance of 1,300 ; but at least it had no difficulty in choosing an appropriate gift to the 